\title{
SOME REACTIONS OF RABBIT SPERMATOZOA TO LIGATION OF THE EPIDIDYMIS
}

\author{
P. GADDUM AND T. D. GLOVER \\ Department of Veterinary Anatomy, University of Liverpool
}

(Received 19th Fune 1964)

\begin{abstract}
Summary. Experiments have been carried out to investigate the reaction of epididymal spermatozoa to interruption of their normal passage through the epididymis. In eighteen rabbits, the epididymis was ligated unilaterally at the distal end of the body, and in a further fifteen the ligature was placed at a point just distal to the head of the epididymis. Samples of spermatozoa from different regions proximal to the ligature were examined in each case for changes in motility, morphology and reactions to certain staining techniques.

It was found that ligation resulted in a distinct pattern of changes in the contained spermatozoa, irrespective of the level at which the epididymis was ligated. Initially these changes involved an enhanced capacity for motility in vitro, decreased eosinophilia and an increased number of coiled tails. In addition, maturation changes in the acrosome and in the location of the protoplasmic droplet occurred. After 14 days of ligation, however, degeneration of the spermatozoa was widespread.

The significance of these events is discussed in relation to the normal maturation of spermatozoa. It is suggested that spermatozoa can mature in situ when the epididymis is ligated, but that the changed environment resulting from ligation appears to superimpose a number of morphological abnormalities on the spermatozoa.
\end{abstract}

\section{INTRODUCTION}

The motility in vitro of mammalian spermatozoa removed from the testis or upper levels of the epididymis is poor compared with that shown by spermatozoa removed from the tail of the epididymis. The increase of motility during the passage of spermatozoa along the ductus epididymidis is widely accepted as reflecting a process of maturation, and it would appear that it is accompanied by an enhanced ability of the spermatozoa to fertilize.

However, Young (1931) showed in guinea-pigs that, if the epididymis is ligated, spermatozoa above the ligature become actively motile in vitro. Thus it seems possible that, in this species at least, spermatozoa can 'mature' at any level of the epididymis, and Young concluded that maturation is primarily a temporal phenomenon. This is not in accordance with the view of Tournade (1913), Redenz (1924), or von Lanz (1926) that secretions of the epididymis are the most potent influence in this process. Salisbury (1956) suggested, as a 
compromise, that both intrinsic and extrinsic factors might be involved, but the issue was far from being settled and the need for further investigation was clear.

The work to be described approaches the problem of maturation in spermatozoa from the point of view of their morphology and certain staining characteristics. The rationale for this lies in the fact that the spermatozoon is also subject to changes in its structure and permeability as it passes through the epididymis, and these, too, have been regarded as indicators of maturation. Migration of the protoplasmic droplet from the neck of the spermatozoon to the end of the mid-piece is a well-known change, and alteration in the shape and dimensions of the acrosome have also been recorded in the rabbit by Bedford (1963), and in the guinea-pig by Fawcett \& Hollenberg (1963). In addition, peculiar changes in the permeability of spermatozoa to eosin seem to occur during their transit through the epididymis (Brochart \& Debatène, 1953; Ortavant, 1953; Glover, 1962a, b), and a conclusive explanation of these effects has never been given.

The maturation of spermatozoa is therefore not easy to define, and it was thought that the use of epididymal ligation would further contribute to an understanding of the problem.

\section{MATERIALS AND METHODS}

Thirty-three adult male rabbits of mixed strain were used in two main experiments. In eighteen rabbits, the epididymis of one side was ligated close to the distal end of the corpus epididymidis (at B, Text-fig. 1), whilst the contra-lateral organ was left intact to serve as a control. These animals will be referred to hereafter as 'the low ligation group'. The operative procedure previously described (Glover, 1960) was followed, but in this instance a single suture was used and no portion of the epididymis was removed.

In the other fifteen rabbits, unilateral ligation of the epididymis was again performed but the ligature was this time passed round the upper end of the corpus epididymidis (at A, Text-fig. 1). These rabbits constitute the 'high ligation group'. It was considered important to have the two groups for comparison, since spermatozoa that are immediately stopped by high ligation (at point $\mathrm{A}$ ) will be younger than those just proximal to a ligature placed at $\mathbf{B}$. Moreover, it is possible that environmental conditions differ at these two levels (see Nicander, 1957).

It is pointed out, in addition, that of the control epididymides twelve were selected at random to provide quantitative estimates, and these have been taken together to serve as control data for both experimental groups (see Tables 1, 2 and 3 ).

Bilateral low ligation of the epididymis was effected on three additional rabbits in order to check some of the more equivocal findings and to determine whether any of the effects of ligation occurred before 6 days. Data from these animals are not included in the main analyses.

Animals in the low ligation group were killed in groups of six on the 6th, 10th and 14th days after operation, whilst five of the high ligation group were killed at the same intervals. 
The rabbits were killed by intravenous injections of sodium pentabarbitone (Euthatal, May and Baker Ltd.) and immediately after death the testes and epididymides were examined macroscopically before being put in normal saline. Within 5 min the contents of a ligated epididymis were sampled at various levels above the ligature (see Text-fig. 1) by making a small incision in the duct and placing one drop of the emergent fluid on to each of two microscope slides. On one, the sample was smeared in the fresh state, then fixed in air and stained by a method based on that of Papanicolaou (1942); the other was smeared after

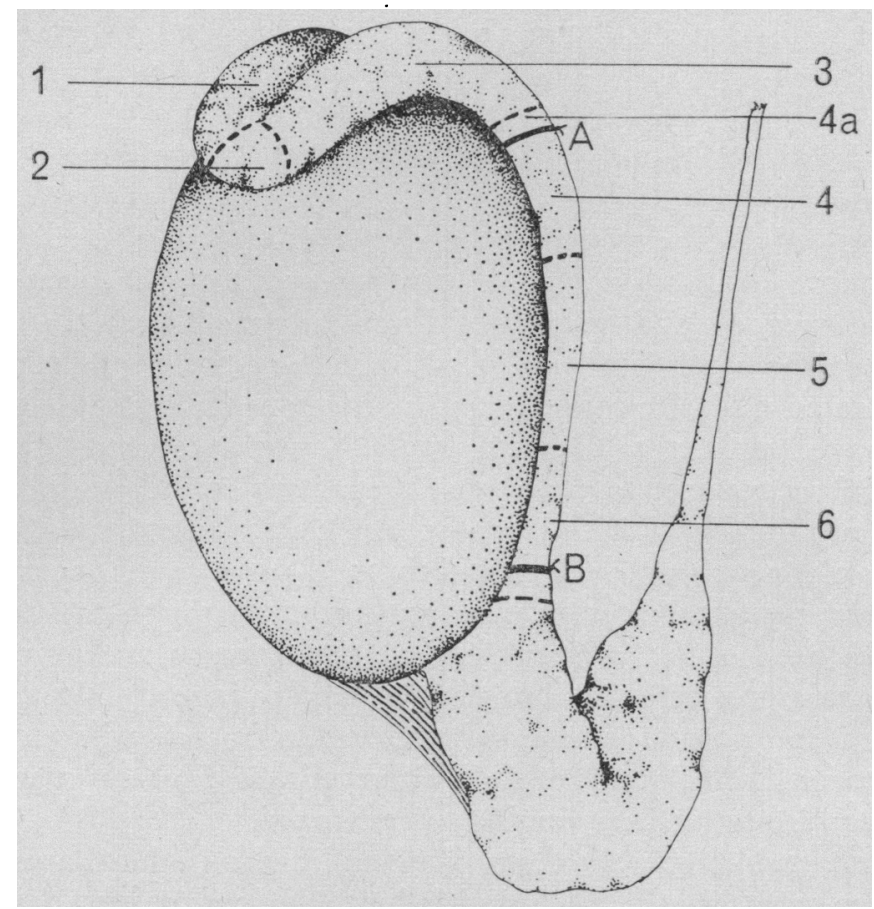

\footnotetext{
Text-Fig. 1. Diagram of the rabbit testis and epididymis to show alternative sites of ligation and regions from which spermatozoa were withdrawn. A, site of high ligation; B, site of low ligation; 1 , initial segment; 2 , caput flexure; 3 , caput epididymidis; 4, upper part of corpus epididymidis; 4a, lowest level from which sperms were taken following high ligation; 5 , middle part of corpus epididymidis; 6 , lower part of corpus epididymidis.
}

being mixed with a drop of aqueous nigrosin eosin, and was then allowed to dry in air at room temperature. The motility of spermatozoa in samples from each level of the epididymis was assessed qualitatively from simple microscopic observation.

Counts of 100 spermatozoa were made on each nigrosin eosin smear at a magnification of 400, and estimates of the incidence of eosinophilic spermatozoa were made together with the estimated occurrence of certain morphological characteristics. These included coiled tails, proximal protoplasmic droplets (situated at the neck of the spermatozoon) distal protoplasmic droplets (migrated towards the end of the mid-piece) and morphologically abnormal droplets. Characteristics of the acrosome were estimated only on smears stained by Papanicolaou's stain, when 100 spermatozoa per slide were counted under oil 
immersion, since these characteristics are less easily defined in nigrosin eosin smears.

All control material was examined in the same way as the experimental material, but counts of acrosome characteristics were made on samples from eight animals only.

For convenience, Tables 1 and 3 only include the results of counts from the initial segment, the caput epididymidis and the region just proximal to the ligature. Counts from levels 2 and 3 have been combined, and those from levels 4 and 5 in the low ligation group have been omitted since they did not show any important individual differences in the particular features recorded in these two tables.

\section{Control material}

\section{RESULTS}

Examination of the contents of control epididymides confirmed earlier reports that more eosinophilic and decapitate spermatozoa occur in samples taken from the lower part of the body of the epididymis than in those taken from either the tail or the head (Glover, 1962a). Also the motility of samples could be roughly correlated with the content of unstained spermatozoa, so that spermatozoa from the tail or head of the epididymis showed greater motility than those from the initial segment or lower part of the corpus epididymidis.

Counts of proximal and distal protoplasmic droplets revealed that in the rabbit the droplet migrates to the end of the mid-piece as the spermatozoa pass from the initial segment (level 1, see Text-fig. 1), through the caput flexure (level 2) to the head of the epididymis (level 3). Thus sperm samples from the head of the epididymis contain abundant spermatozoa with migrated droplets. Nevertheless, these spermatozoa show much less propensity for motility in vitro than spermatozoa from the tail of the epididymis, and in any case are accompanied by many immotile eosinophilic spermatozoa.

From smears stained by the Papanicolaou method, there appeared to be four types of spermatozoa distinguishable by their acrosomes:

(1) The acrosome was closely applied to the nucleus and formed an almost continuous outline with the postnuclear cap (see Pl. 1, Fig. 4).

(2) The acrosome was expanded but had a distinct outline (see Pl. 1, Fig. 3).

(3) Spermatozoa with a 'swollen' and very pale-staining acrosome, the outline of which was quite indistinct (see Pl. 1, Fig. 3).

(4) Spermatozoa that appeared to have no acrosome.

Quantitative cstimates of these different types of spermatozoa showed that in samples from the tail of the epididymis the ratio of type 1 to type 2 was $94: 5$, whereas in those from the head of the epididymis it was $2: 78$. Type 4 occurred but rarely, whilst type 3 was more common in samples withdrawn from upper regions of the epididymis than in those from the tail (see Table 4).

\section{Low ligation group}

Overall distension of the epididymis proximal to the point of ligation occurred in all cases. However, as previously reported (Glover, 1962a, b) there were discrete patches where the tubule was particularly distended and cream in 


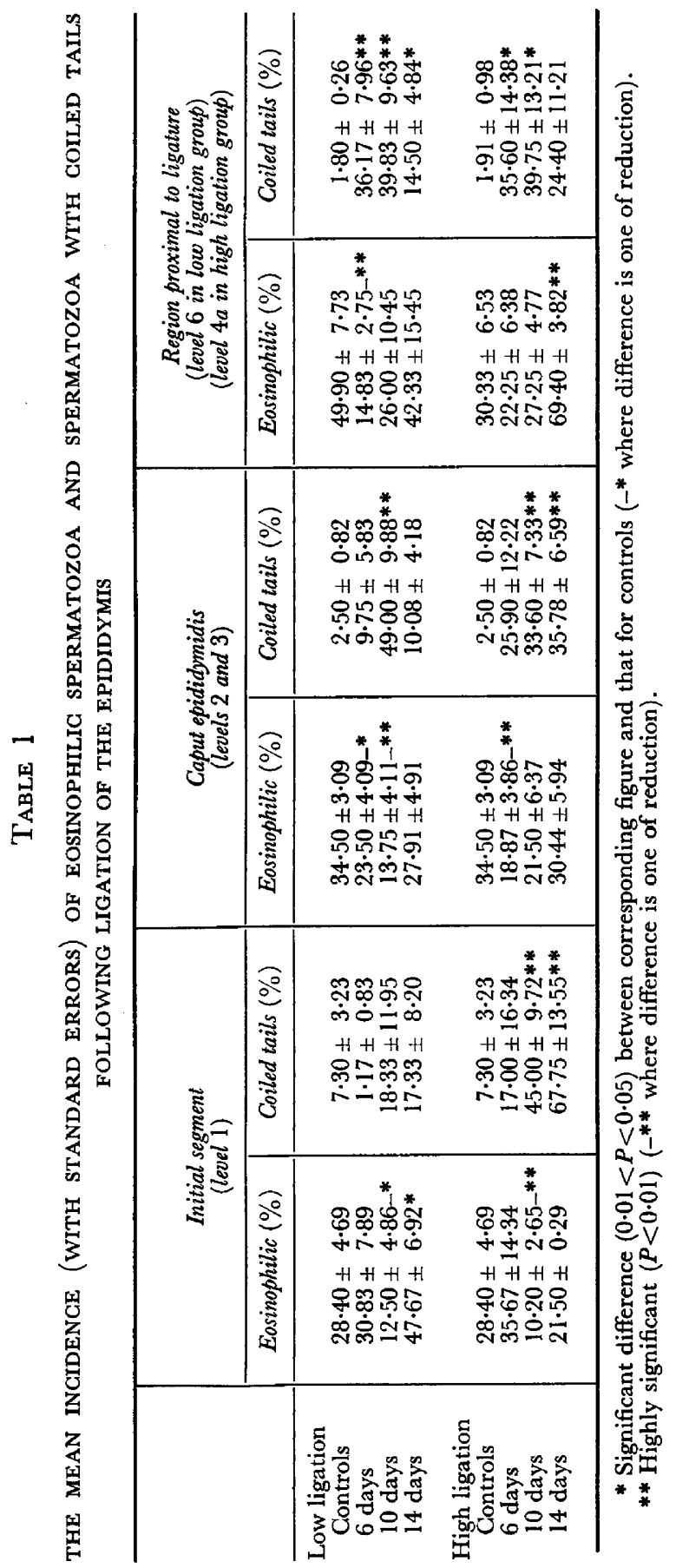


colour. After 6 days of ligation, the whole of the corpus epididymidis was distended in this way, whilst the head and initial segment were unaffected. Longer periods of ligation, however, resulted in a variable distribution of these patches (for example, see Pl. 2, Fig. 1). They were evidently due to excessive accumulations of spermatozoa.

After 6 days the motility of spermatozoa from all three levels of the body of the epididymis was better than those of control samples, but after 10 days it was from the head of the epididymis and the initial segment that the most actively motile spermatozoa were obtained. After 14 days there was an overall reduction in the motility of the samples.

\section{TABLE 2}

THE MEAN PROPORTION (WITH STANDARD ERRORS) OF SPERMATOZOA WITH PROXIMAL DROPLETS AND DISTAL DROPLETS IN THE INITIAL SEGMENT (LEVEL 1)

\begin{tabular}{l|c|c|c|c}
\hline \multirow{2}{*}{} & \multicolumn{2}{|c|}{ Low ligation } & \multicolumn{2}{c}{ High ligation } \\
\cline { 2 - 5 } & Proximal $(\%)$ & Distal $(\%)$ & Proximal $(\%)$ & Distal $(\%)$ \\
\hline Controls & $58 \cdot 10 \pm 3 \cdot 29$ & $0 \cdot 90 \pm 0 \cdot 60$ & $58 \cdot 10 \pm 3 \cdot 29$ & $0 \cdot 90 \pm 0 \cdot 60$ \\
6 days & $50 \cdot 17 \pm 9 \cdot 82$ & $4 \cdot 83 \pm 3 \cdot 57$ & $41 \cdot 50 \pm 21 \cdot 43$ & $4 \cdot 25 \pm 1 \cdot 97$ \\
10 days & $40 \cdot 83 \pm 13 \cdot 40$ & $8 \cdot 17 \pm 4 \cdot 81$ & $17 \cdot 60 \pm 7 \cdot 13 * *$ & $13 \cdot 40 \pm 5 \cdot 71 *$ \\
14 days & $14 \cdot 83 \pm 7 \cdot 15-* *$ & $9 \cdot 33 \pm 3 \cdot 42 *$ & $9 \cdot 75 \pm 5 \cdot 59-* *$ & $4 \cdot 75 \pm 2 \cdot 95$ \\
& & & & \\
\hline
\end{tabular}

* Significant difference $(0.01<P<0.05)$ between corresponding figure and that for controls (-* where difference is one of reduction).

** Highly significant difference $(P<0 \cdot 01)(-* *$ where difference is one of reduction).

Changes in motility were directly related to the incidence of spermatozoa with coiled tails but inversely related to the incidence of eosinophilic spermatozoa. Table 1 shows that the proportion of spermatozoa with coiled tails rose significantly at level 6 after 6 days of ligation, and at levels 2 and 3 after 10 days of ligation; after 14 days the proportions were reduced at all levels of the epididymis. By contrast, the incidence of eosinophilic spermatozoa was significantly reduced at level 6 after 6 days, and in the more proximal regions after 10 days. It appears, therefore, that ligation resulted first in the spermatozoa acquiring an increased capacity for motility in vitro; this was reflected in nigrosin eosin smears by a higher incidence of unstained spermatozoa and many spermatozoa with coiled tails. It was followed by the progressive degeneration of spermatozoa, the onset of which was indicated by an increased proportion of eosinophilic spermatozoa in samples withdrawn after 14 days of ligation.

With regard to the migration of the protoplasmic droplet, results showed that in samples from level 1 the proportion of spermatozoa with proximal

\section{EXPLANATION OF PLATE 1}

Smears of spermatozoa from a control epididymis. $\times 1500$.

FIG. 1. Spermatozoa from the initial segment stained with aqueous nigrosin eosin.

FIG. 2. Spermatozoa from the tail of the epididymis stained with aqueous nigrosin eosin.

Fig. 3. Spermatozoa from the caput flexure region stained by Papanicolaou's technique. The photograph shows one spermatozoon with type 2 acrosome (arrowed, considered to be immature) and two spermatozoa with type 3 acrosomes (considered to be dead) for comparison.

FIG. 4. Spermatozoa from the tail of the epididymis stained by Papanicolaou's technique. 
PLATE 1

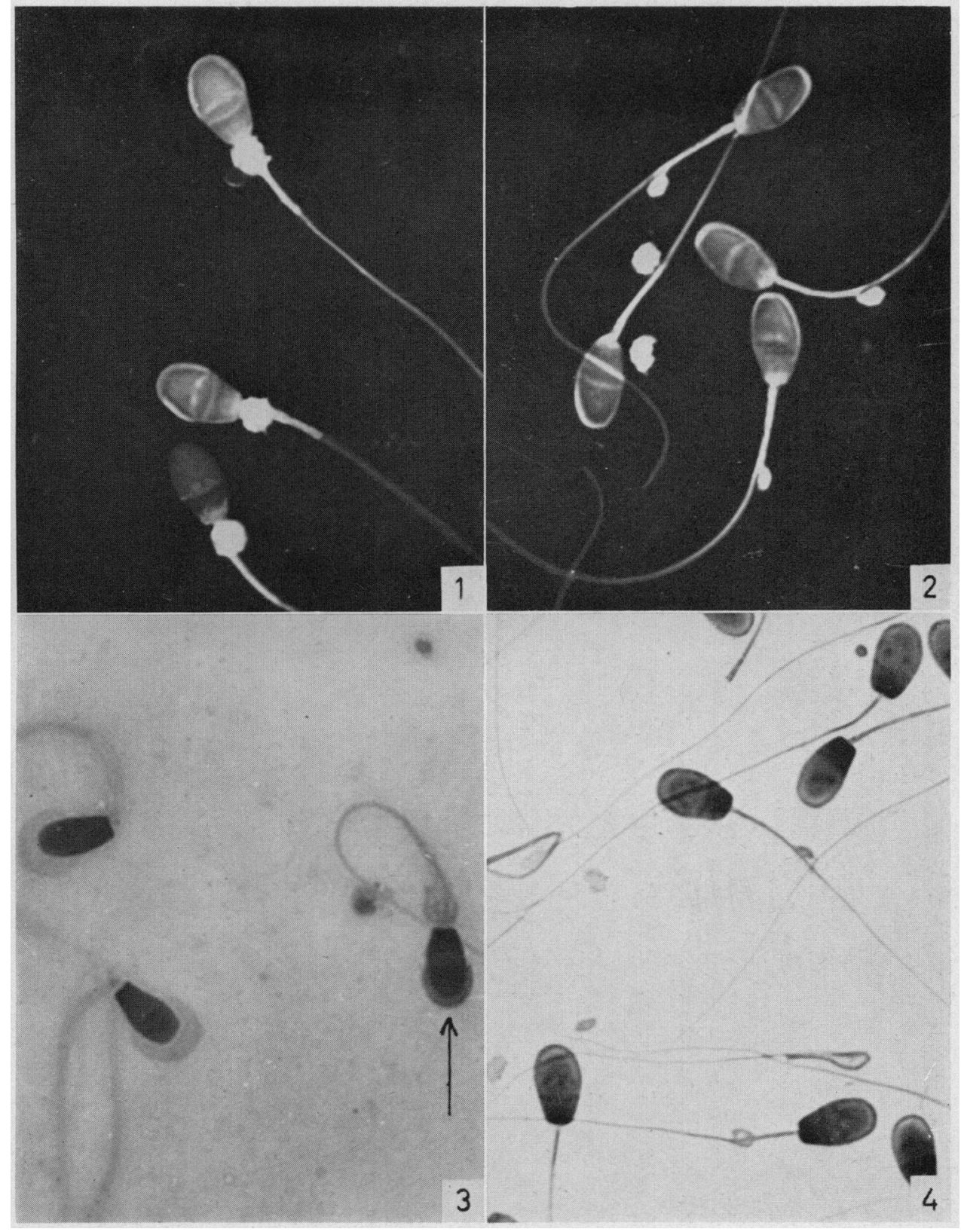

Facing p. 124) 
PIAX'E' 2

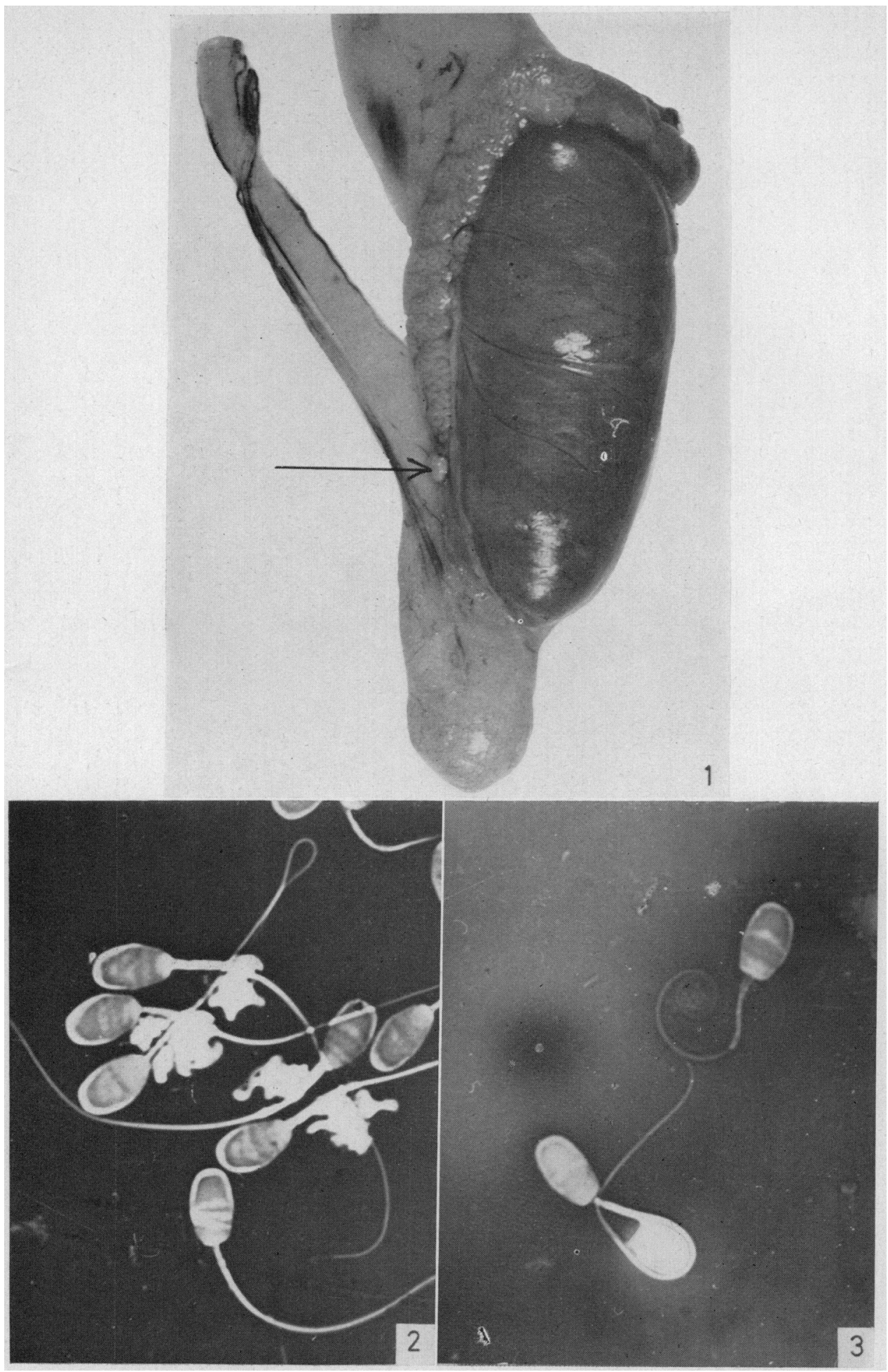


droplets was significantly reduced after 14 days, but an increased incidence of distal droplets was less significant (see Table 2). In addition, some of the spermatozoa from all levels had morphologically abnormal droplets after 6 days of ligation and these took the form of swollen or fragmenting droplets (see Pl. 2, Figs. 2 and 3). There was considerable variation between individuals in the proportion of these abnormalities, but a highly significant increase in their occurrence was apparent after 14 days in samples from the head of the epididymis (see Table 3 ). It might be noted in passing that swollen droplets were frequently associated with coiled tails (see Pl. 2, Fig. 2).

\section{TABle 3}

THE MEAN INCIDENCE (WITH STANDARD ERRORS) OF SPERMATOZOA WITH ABNORMAL PROTOPLASMIC DROPLETS

\begin{tabular}{|c|c|c|c|}
\hline & $\begin{array}{l}\text { Initial segment } \\
(\text { level } 1)\end{array}$ & $\begin{array}{l}\text { Caput epididymidis } \\
\quad(\text { levels } 2 \text { and } 3)\end{array}$ & $\begin{array}{l}\text { Region proximal to ligature } \\
\text { (level } 6 \text { in low ligation) } \\
\text { (level } 4 a \text { in high ligation) }\end{array}$ \\
\hline $\begin{array}{l}\text { Low ligation } \\
\text { Controls } \\
6 \text { days } \\
10 \text { days } \\
14 \text { days }\end{array}$ & $\begin{aligned} & 0 \cdot 00 \\
& 2 \cdot 00 \pm 0.73 \\
& 7 \cdot 67 \pm 3 \cdot 92 \\
& 10 \cdot 33 \pm 5 \cdot 15\end{aligned}$ & $\begin{array}{c}0.92 \pm 0.42 \\
3 \cdot 58 \pm 1 \cdot 55 \\
5 \cdot 75 \pm 2 \cdot 52 \\
15 \cdot 66 \pm 1 \cdot 25 * *\end{array}$ & $\begin{array}{l}1 \cdot 10 \pm 1 \cdot 10 \\
5 \cdot 50 \pm 2 \cdot 51 \\
4 \cdot 67 \pm 3 \cdot 03 \\
6 \cdot 33 \pm 3 \cdot 35\end{array}$ \\
\hline $\begin{array}{l}\text { High ligation } \\
\text { Controls } \\
6 \text { days } \\
10 \text { days } \\
14 \text { days }\end{array}$ & $\begin{array}{l}0 \cdot 00 \\
2 \cdot 75 \pm 2 \cdot 14 \\
2 \cdot 60 \pm 1 \cdot 44 \\
3 \cdot 00 \pm 1 \cdot 78\end{array}$ & $\begin{array}{c}0 \cdot 92 \pm 0 \cdot 42 \\
1 \cdot 80 \pm 0 \cdot 66 \\
19 \cdot 80 \pm 4 \cdot 14 * * \\
20 \cdot 12 \pm 8 \cdot 09^{*}\end{array}$ & $\begin{array}{l}0 \cdot 33 \pm 0 \cdot 24 \\
9 \cdot 00 \pm 6 \cdot 61 \\
9 \cdot 50 \pm 2 \cdot 72 * * \\
2 \cdot 80 \pm 0 \cdot 86^{*}\end{array}$ \\
\hline
\end{tabular}

* Significant difference $(0.01<P<0.05)$ between corresponding figure and that for controls.

** Highly significant difference $(P<0.01)$.

Differential counts of acrosome types in samples taken from level 2 showed that low ligation of the epididymis eventually results in a significant increase in this area of the proportion of spermatozoa with type 1 acrosomes. In two out of the three animals examined after 3 days of ligation, the percentage frequency of type 1 acrosomes was 68 and 88 respectively, whilst in the third animal no significant increase in this type of acrosome was discernible. After 6 days, a highly significant increase in the occurrence of type 1 acrosomes was apparent at this level in four out of five experimental animals, and at 10 and 14 days some stability appeared to have been reached (see Table 4). A high percentage of type 1 acrosomes was accompanied by a correspondingly low incidence of type 2 . The proportion of type 3 acrosomes progressively decreased after ligation, but this trend only became significant after 10 days.

\section{EXPLANATION OF PLATE 2}

Frg. 1. Appearance of the testis and epididymis after 10 days of low epididymal ligation. Note marked distension of tubule proximal to the ligature. Conspicuous convolutions throughout the body and in part of the head. Arrow indicates site of ligation.

FIG. 2. Spermatozoa from the caput epididymidis following epididymal ligation showing typical fragmentation of the protoplasmic droplet (stained with aqueous nigrosin eosin). $\times 1500$.

Fig. 3. Spermatozoa from the caput epididymidis following epididymal ligation showing typical coiling of the tail. Note one spermatozoon shows another type of droplet abnormality [see text]. (Stained with aqueous nigrosin eosin). $\times 1500$. 


\section{High ligation group}

Generally speaking, the effects of high ligation of the epididymis resembled those of low ligation, but differences in degree and time of onset of the changes are of interest. Overall distension of the epididymis proximal to the ligature was again apparent, with discrete creamy-coloured patches occurring randomly. High ligation often caused swelling of the seminiferous tubules also, so that white patches appeared on the surface of the testis.

The spermatozoa removed from level 4a (see Text-fig. 1) were the first to show an enhanced motility, whilst spermatozoa from more proximal levels did

\section{TABLE 4}

THE MEAN INGIDENGE (WITH STANDARD ERRORS) OF SPERMATOZOA WITH DIFFERENT TYPES OF ACROSOME AT THE CAPUT FLEXURE FOLLOWING LIGATION OF THE EPIDIDYMIS. CONTROL DATA FROM BOTH THE CAPUT FLEXURE AND THE GAUDA EPIDIDYMIDIS ARE ALSO SHOWN FOR GOMPARISON

\begin{tabular}{|c|c|c|c|c|c|}
\hline & $\mid \begin{array}{c}\text { No. } \\
\text { samples }\end{array}$ & Type $1 \dagger$ & Type 2 & Type 3 & Type 4 \\
\hline $\begin{array}{l}\text { Controls } \\
\text { (Caput flexure) }\end{array}$ & 8 & $2 \cdot 42 \pm 2 \cdot 21$ & $77 \cdot 71 \pm 5 \cdot 48$ & $17 \cdot 00 \pm 5 \cdot 09$ & $2.85 \pm 0.83$ \\
\hline $\begin{array}{l}\text { Low ligation } \\
3 \text { days } \\
6 \text { days } \\
10 \text { days } \\
14 \text { days }\end{array}$ & $\begin{array}{l}3 \\
5 \\
4 \\
4\end{array}$ & $\begin{array}{l}56 \cdot 00 \pm 21 \cdot 63^{*} \\
71 \cdot 20 \pm 18 \cdot 11^{* *} \\
92 \cdot 25 \pm 1 \cdot 97^{* *} \\
93 \cdot 75 \pm 0 \cdot 24^{* *}\end{array}$ & $\begin{array}{r}34 \cdot 00 \pm 23.26 \\
18 \cdot 40 \pm 14 \cdot 44-* * \\
6 \cdot 00 \pm 2.27-* * \\
4 \cdot 25 \pm 0 \cdot 48-* *\end{array}$ & $\begin{array}{l}7 \cdot 67 \pm 1 \cdot 20 \\
8 \cdot 00 \pm 3 \cdot 89 \\
1.00 \pm 0 \cdot 22-* * \\
0 \cdot 25 \pm 0.24-* *\end{array}$ & $\begin{array}{l}2.33 \pm 1.45 \\
2.40 \pm 1.03 \\
0.75 \pm 0.48 \\
1.75 \pm 0.63\end{array}$ \\
\hline $\begin{array}{l}\text { High ligation } \\
6 \text { days } \\
10 \text { days } \\
14 \text { days }\end{array}$ & $\begin{array}{l}3 \\
4 \\
4\end{array}$ & $\begin{array}{l}67 \cdot 33 \pm 19 \cdot 33^{* *} \\
96 \cdot 75 \pm 1 \cdot 60^{* *} \\
92 \cdot 25 \pm 2 \cdot 53^{* *}\end{array}$ & $\begin{array}{c}28.00 \pm 25 \cdot 50 \\
1.75 \pm 1.44-* * \\
1.50 \pm 0.96-* *\end{array}$ & $\begin{array}{l}2 \cdot 67 \pm 2 \cdot 19-* \\
0 \cdot 00-* * \\
0 \cdot 25 \pm 0 \cdot 24-* *\end{array}$ & $\begin{array}{l}2 \cdot 00 \pm 0 \cdot 58 \\
1 \cdot 50 \pm 1 \cdot 50 \\
6 \cdot 00 \pm 2 \cdot 71\end{array}$ \\
\hline $\begin{array}{l}\text { Controls } \\
\text { (Cauda epididymidis) }\end{array}$ & 8 & $94 \cdot 00 \pm 2 \cdot 25$ & $4 \cdot 63 \pm 2 \cdot 21$ & $0 \cdot 25 \pm 0 \cdot 17$ & $1 \cdot 12 \pm 0 \cdot 44$ \\
\hline
\end{tabular}

+ See text for description of different types.

* Significant difference $(0.01<P<0.05)$ between corresponding figure and that for controls $(-*$ where difference is one of reduction).

** Highly significant difference $(P<0.01)(-* *$ where difference is one of reduction).

not exhibit this change until 10 to 14 days of ligation had elapsed. These changes are similar in principle to those seen in the low ligation group, but were more pronounced, for after 6 days samples from the caput epididymidis exhibited wave motion, whilst after 14 days virtually all spermatozoa from level $4 \mathrm{a}$ were already immotile.

Again, there was an inverse relationship between motility and eosinophilia in samples from each level, with the exception of level 4a where the proportion of eosinophilic spermatozoa was not significantly reduced at any time (see Table 1).

The incidence of spermatozoa with coiled tails followed a similar pattern in the initial stages of ligation to that seen in the low ligation group, namely an increase at 6 days in the region just proximal to the ligature, and a similar increase at 10 days in the caput epididymidis. By contrast, however, a high 
incidence of these spermatozoa occurred in the initial segment also at 10 days, and the proportion was increased at 14 days.

Migration of the protoplasmic droplet occurred earlier in this group, for, after 10 days, counts on samples from level 1 indicated a significant decrease in the proportion of spermatozoa with proximal droplets. This was accompanied by a slight increase in the occurrence of spermatozoa with distal droplets (see Table 2). Droplet abnormalities of a similar type to those already described were again evident but they also appeared earlier than in the low ligation group (see Table 3 ) and were to be found just proximal to the ligature as well as in the head.

With regard to changes in the acrosome, counts on samples from level 2 showed that after 6 days there was a preponderance of type 1 acrosomes in two animals, whilst in a third animal, the proportions did not differ significantly from the controls. However, after 10 and 14 days, a high incidence of type 1 was found in all the experimental animals (see Table 4).

\section{DISGUSSION}

This work provides further evidence that obstruction of normal flow in the epididymis of the rabbit results in a distinct pattern of changes in the contained spermatozoa. This is characterized by the development of an increased capacity for in-vitro motility, first by those spermatozoa immediately above the site of occlusion and later by those at higher levels of the epididymis. Observations of the motility, morphology and differential staining reactions, however, all indicate that this apparent 'awakening' of the spermatozoa is soon followed by their degeneration. At all events, the findings suggest that when spermatozoa are arrested during their passage through the epididymis, they undergo in situ certain changes that are usually associated with maturation. That some of the changes occurred more rapidly after high ligation than low ligation is probably due to the earlier arrest of sperm flow in the epididymis following high ligation. Thus samples of spermatozoa from the initial segment, for instance, would show a large proportion of immature spermatozoa for a longer period of time after low ligation, because replenishment from the testis would not be blocked as quickly.

The question still remains as to whether changes induced by ligation of the epididymis concern only the motility and staining reaction of the spermatozoa or whether they truly represent so-called maturation changes. The morphological features of the spermatozoa were of value in this connexion. Results show that under the highly artificial conditions of ligation of the epididymis, protoplasmic droplets can migrate to the end of the mid-piece whilst the spermatozoa are still within the initial segment. Moreover, abundant spermatozoa with contracted acrosomes can also be found at the level of the caput flexure following epididymal ligation, whereas in the intact animal a preponderance of spermatozoa with expanded acrosomes is normally found at this level.

The 'cytoplasmic cap' which has been described in the spermatozoa of several domestic species (Rao, 1958) is probably analogous to the type 2 acrosome observed in this work, but suggestions that it is a normal feature (Rao \& Berry, 1949) or that it denotes functional immaturity (McKenzie, Miller \& 
Bauguess, 1938) have been challenged by Hancock (1952, 1956). He believed that the presence of the 'cap' reflected a post-mortem change in the acrosome. However, in the present work it has been possible, with the use of Papanicolaou's staining technique, to distinguish two kinds of 'swollen' acrosome, and it is considered that these represent immature and dead spermatozoa. Thus dead spermatozoa could be discounted when assessing the proportions of mature and immature forms.

The data from the counts of acrosome types suggest that observed increases in the motility of spermatozoa following ligation of the epididymis reflect the degree of maturation. But further evidence from this study indicates that this is not a precise relationship.

For example, a number of spermatozoa develop an abnormality of their protoplasmic droplet. A significant increase in the incidence of this type of spermatozoon after 14 days is probably due largely to fragmenting droplets and may be purely a sign of degeneration, but many swollen droplets occurred earlier in association with coiled tailed spermatozoa. The presence of these is obscured in the data because they were counted as coiled tails only.

Secondly, the high incidence of spermatozoa with coiled tails, which occurred in both the high ligation and low ligation groups, is not a normal feature of maturation. For the purpose of this investigation all forms of contorted tails or mid-pieces were classified as 'coiled tails'. Swanson \& Boyd (1962) in a study of coiled tails in both ejaculated and epididymal spermatozoa of bulls, reported that they were associated with poor motility. By contrast, the present investigation has shown that epididymal spermatozoa trapped in a ligated tubule for only a short period, become very actively motile, yet smears of such spermatozoa show a fairly high proportion of coiled tails. It is possible that some of these coiled tails are produced in vitro, for close observation of fresh samples before smearing showed that the spermatozoa did not have coiled tails at that time, although they exhibited an unusual form of convulsive movement. By comparison, the high incidence of coiled tails in smears taken at later stages of the experiment are more likely to have been actually produced in vivo, since they could be clearly seen in fresh samples which showed very poor motility.

The development of abnormal motility after epididymal ligation is of interest in connexion with the observations of Blandau \& Rumery (1961) that, in the rat, spermatozoa from the head of the epididymis normally exhibit a form of movement which differs from that of mature spermatozoa. They suggest that this may have a bearing on the relative inability of immature sperms to fertilize, and it would certainly seem valuable to carry out fertility tests in the rabbit after epididymal ligation.

The time of onset of changes in the spermatozoa is also of interest, for contraction of the acrosome was seen to have taken place in many spermatozoa as early as 3 days following epididymal obstruction. Normally the rate of transit of spermatozoa through the epididymis of the rabbit is between 5 and 12 days (Edwards, 1940; Koefoed-Johnsen, 1961; Amann \& Koefoed-Johnsen, 1963), but this concerns their passage from the testis to the ductus deferens, and most spermatozoa show signs of maturation by the time they enter the tail of the epididymis. It could well be, therefore, that rabbit sperms only require about 
3 days to attain maturity and that ligation of the epididymis does not significantly affect this. Degeneration of the spermatozoa could also be interpreted as a mere extension of the maturation process.

In previous work there has been some doubt about the significance of eosinophilia in epididymal spermatozoa. Amann \& Almquist (1962) believed it to be due to a change in the permeability of the cells, and, whilst this is undoubtedly so, the origin of such a change is more obscure. A high degree of eosinophilia is invariably associated with poor overall motility in fresh samples and many decapitated spermatozoa in smears, and, following ligation of the epididymis, it is strongly suggestive of degeneration and possible ageing of the spermatozoa. This may not, of course, apply to eosinophilic spermatozoa from intact epididymides.

The present results in the rabbit thus appear to be in accordance with the findings of Young (1931) in the guinea-pig, that spermatozoa can mature in situ when their normal flow is arrested by ligation of the epididymis, because increases in motility were accompanied by morphological changes that are normally associated with maturation.

Nevertheless, accumulation of fluid as well as of spermatozoa results from ligation of the epididymis, so that the environment of spermatozoa at any one level of the duct must differ from that in the normal animal. It is suggested, therefore, that the altered environment could be largely responsible for abnormal features in motility and morphology and that these are superimposed upon an otherwise normal process of maturation.

\section{ACKNOWLEDGMENTS}

This work was carried out with the aid of grants from the Wellcome Trust and the Population Council Incorporated. Our thanks are due to Professor A. S. King for his interest in the work, and also to members of the technical staff for their skilled assistance.

\section{REFERENCES}

Amann, R. P. \& Almquist, J. O. (1962) Reproductive capacity of dairy bulls. VII. Morphology of epididymal sperm. F. Dairy Sci.45, 1516.

Amans, R. P. \& Koefoed-Johnsen, H. H. (1963) Fortsatte undersogelser over spermiedannelse og spermietransport hos kaniner. Aarsberetn. Inst. Sterilitetsforskn. K. Vet-og Landbohøjsk. (Kbh.), p. 237 (from English summary).

BEDford, J. M. (1963) Morphological changes in rabbit spermatozoa during passage through the epididymis. 7. Reprod. Fertil. 5, 169.

BLANDau, R. J. \& RUMERY, R. E. (1961) Fertilizing capacity of rat spermatozoa recovered from various segments of the epididymis. Anat. Rec. 139, 209.

Brochart, M. \& Debatène, D. (1953) Diminution de la perméabilité à l'éosine de la capsule lipoidique de la tête des spermatoides de ruminants domestiques après l'éjaculation. C.R. Soc. Biol., Paris, $147,20$.

Edwards, J. (1940) The effect of unilateral castration on spermatogenesis. Proc. roy. Soc. B, 128, 407.

Fawcett, D. W. \& Hollenberg, R. D. (1963) Changes in the acrosome of guinea pig spermatozoa during passage through the epididymis. Z. Zellforsch. 60, 276.

Glover, T. D. (1960) Spermatozoa from the isolated cauda epididymidis of rabbits and some effects of artificial cryptorchidism. F. Reprod. Fertil. 1, 121.

Glover, T. D. (1962a) The response of rabbit spermatozoa to artificial cryptorchidism and ligation of the epididymis. 7. Endocrin. 23, 317. 
Glover, T. D. (1962b) The reaction of rabbit spermatozoa to nigrosin eosin following ligation of the epididymis. Int. F. Fertil. 7, 1.

Hancock, J. L. (1952) The morphology of bull spermatozoa. 7. exp. Biol. 29, 445.

HANcock, J. L. (1956) The morphology of boar spermatozoa. 7. roy. micr. Soc. 76, 84.

Koefoed-Johnsen, H. H. (1961) Om epididymis' function. I. Spermiernes passagehastighed gennem epididymis. Aarsberetn. Inst. Sterilitetsforskn. K. Vet-ag Landbohojsk (Kbh.), p. 57 (from English summary).

LANz, T. von (1926) Über Bau und Funktion des Nebenhodens und seine Abhängigkeit von der Keimdrüse. Z. Anat. Entwickl. Gesch. 80, 177.

McKenzie, F. F., Miller, J. C. \& Bauguess, L. C. (1938) The reproductive organs and semen of the boar. Res. Bull. Mo. agric. Exp. Sta. 279.

NicANDER, L. (1957) On the regional histology and cytochemistry of the ductus epididymidis in rabbits. Acta morph. neerl.-scand. 1, 99.

Ortavant, R. (1953) Existence d'une phase critique dans la maturation épididymaire des spermatoides de bélier et de taureau. C.R. Soc. Biol., Paris, 147, 1552.

Papanicolaou, G. N. (1942) A new procedure for staining vaginal smears. Science, 95, 438.

Rao, C. K. \& BerRx, R. O. (1949) The cytoplasmic drop and the cytoplasmic cap in the development of boar spermatozoa. Amer. 7. vet. Res. 10, 357.

Rao, G. K. (1958) Studies on the morphology and development of the spermatozoa of farm animals. Indian vet. . $35,268$.

Redenz, E. (1924) Versuch einer biologischen Morphologie des Nebenhodens. Arch. mikr. Anat. 103, 593.

Salisbury, G. W. (1956) The function of the epididymis of the bull. I. A theory for the activation of spermatozoan motility. Tijdschr. Diergeneesk. 81, 616.

Swanson, E. W. \& Boyd, L. J. (1962) Factors affecting coiled-tail spermatozoa in the bull. Amer. $\mathcal{J}$. vet. Res. 23, 300.

Tournade, A. (1913) Différence de motilité des spermatozoides prélevés dans les divers segments de l'épididyme. C.R. Soc. Biol., Paris, 74, 738.

Young, W. G. (1931) A study of the function of the epididymis. III. Functional changes undergone by spermatozoa during their passage through the epididymis and vas deferens in the guinea pig. $\mathcal{F}$. exp. Biol. 8, 151. 